(c) CEDA/TU, 2015, US Library of Congress, Catalog Card No. : 79-915209, ISSN: 2091-0339

The Journal of Development and Administrative Studies (JODAS), Vol. 23(1-2), pp. 55-68

\title{
The Determinants of Fertility among Women of Reproductive Age in Nepal
}

\author{
- Mahendra Prasad Sharma*
}

\begin{abstract}
This study is conducted on determinants of fertility among women of reproductive age in Nepal. The study takes into account some demographic, socio-cultural, economic and spatial variables. Fertility trends are estimated from the date obtained in the 1996, 2001, and 2006 NDHS with information gathered in the 2011 NDHS. Fertility declined from 4.6 births per woman in the 1996 NFHS to 2.6 births per woman in the $2011 \mathrm{NDHS}$ - a drop of two births per woman in the past 15 years. The decline in fertility is most pronounced in the five years between 2001 and 2006 (a one-child decline). Fertility has declined in every age group over the past 15 years, with largest decline seen among women 25-34 years. But over the past 5 years the largest decline is observed among women 20-24 years. Many factors may have contributed to this quick decline fertility in Nepal, including improved communication and greater access to modern methods of contraception. Extended spousal separations due to migrants seeking work in foreign countries, especially the Gulf countries and other Southeast Asian countries, may be another reason for the fertility decline (NDHS Report 2012). The multivariate analysis is used to show the strength of relationship of fertility with its correlates. It estimates the effect of socio-economic and demographic as well as spatial variables on total Children Ever Born (CEB). This study also attempts to find out variation of fertility among women by using frequency table, rate, ratio, percentage, cross tabulation, correlation and regression analysis and mean CEB. The result shows that when other factors remain unchanged, age of respondents at first birth and educational attainment have strong and significant negative impact on fertility. Similarly son who have died, daughter who have died, parity at sterilization and age at sterilization have strong and significant positive impact on fertility whereas regions, type of place of residence, age at marriage and destination India have weak positive impact on fertility.
\end{abstract}

Keywords: Age of marrage, fertility, reproductive age, religion, correlation and regression analysis.

JEL classification: $\mathrm{J}_{10}, \mathrm{~J}_{12}, \mathrm{~J}_{13}$, and $\mathrm{J}_{15}$

\footnotetext{
* Mr. Sharma is Associate Professor at Central Department of Population Studies, Tribhuvan University, Kirtipur
} 


\section{Introduction}

Human fertility as one of the major component of population growth has become an interesting topics in population studies after Malthus (1766-1834 A.D). The need for the study of fertility cannot be overemphasized because of its great impact on both population growth rate and on other social, economic, spatial and cultural parameters. The study of the factors related to high fertility levels, and those associated with fertility decline, assumes great importance. There is high rate of population growth in most developing countries which is generally considered to be a determinant to their rapid economic development (UN, 1973). The populations of Nepal increased very little until 1941 and it has been growing quite rapidly since then. There were 5.6 million populations in 1911 and it reached 6.28 million in 1941 A.D. Then it increased by 6.7 million between $1952 / 54$ A.D. (8.3 million) and 1981 A.D. (15 million). The population of Nepal in mid-2011 A.D has crossed 26.6million. The rate of national population growth has 1.4 percent per year. The crude birth rate of Nepal is 25 and the crude death rate is 6 per 1000 also proves the high population growth of the country (PRB, 2011).The rapid population growth cannot be controlled without appropriate study of determinant factors of fertility of the women. But the demographic information shows that Nepal's TFR was above 5.0 until the early1990s (MOH, 1993) and above 4.0 even in 2001 (MOH 2001). The status of Nepal among the major demographic and other indicators is very poor. However, the TFR decreased about 25 percent (4.1 births per women in 2001 to 3.1 births per women in 2006) between the two surveys. The NDHS 2011 identify TFR of Nepal is 2.6. This is 1.6 in urban and 2.8 in rural areas. It is still essential to identify the risk factors associated with high fertility and to provide services to address those who are at risk. To develop effective strategies for fertility control, it is necessary to identify the factors supporting to higher fertility. The total fertility rate is still high compared to that of other developing countries (PRB, 2011). As mentioned NDHS report 2012, the decline in fertility is most pronounced in the five years between 2001 and 2006 (a one-child decline). It is prominent needs to identify the fertility differentials among Nepali women. The determinant factors of fertility have played significant role to make small family size. It is hoped that exploring the determinant factors of fertility may be helpful to make national policies to reduce rapid population growth in some extent.

Indeed, one would expect that government's population policy would address the population problem directly, but the situation cannot be controlled only by the formulation of policies. Robust and rigorous regime of research has to be conducted to provide information on the exact cause and effect relationship or association of variables with fertility. Many multi-variants studies have been conducted to examine the causal factors linked with fertility. This paper is an attempt to examine the demographic, socio-culture, economic, and spatial factors for fertility differentials in Nepal. Fertility is not only biological as opposed to social; it is also historically and culturally specific, structured by a particular set of social assumptions. Issues surrounding childbearing and childrearing keep core family-related behaviors, both in social science theory and in widely shared perceptions of family life. They also remain vitally important for range 
of demographic, economic, socio- cultural, spatial and political issues. There are some studies on determinants of fertility in Nepal but those studies still have not been able to identify major variables that impact and make significant relationship with fertility. So this study is an attempt to fill the gap on this issue with the help of NDHS 2006 data since NDHS 2012 report has already mentioned the decline in fertility is pronounced mainly in the five years between 2001 and 2006 (a one-child decline).

\section{Review of Literatures}

The theory of demographic transition is an effort to explain the behaviors of demographic variables (explicitly of the birth rate, death rate and growth rate) in process of transition from uncontrolled fertility to controlled fertility, with reference to the process of development.

The economic theory of fertility commonly refers to fertility as a demand for children, which is a function of their cost and family income. This theory tested by Becker (1960) using American data on three variables: number of children, quality of children and family income. He has concluded that although one would expect that families with higher income want more children than families with lower income, the latter possess more children because they lack the knowledge of contraceptives and they have "lower quality" children.

There are some fertility theories that explain the role of socio economic factors to affect the choice of family size at individual household level. The threshold hypothesis was developed by United Nation (UN) in the years 1963 indicates that there is an inter-relation between fertility and general socio-economic development of the society. According to this theory fertility begins decrease after a society has reached a certain level of social development. Family planning programs may not be successful unless determinants of fertility by caste/ ethnic groups are well studied. However, there are few research works that are directly related with particular ethnic group (UN, 1973).Davis and Blake (1956) have developed a framework for looking at the causes of a particular fertility determinant. They recognize that the proximate determinants of natural fertility are a set of biological and behavioral factors that affect fertility directly through socio-economic and other background variables. Davis and Blake list three major variables determining fertility: intercourse, conception, and gestation. These are further broken down into 11 distinct sub variables, which are known as the proximate fertility determinants, but all these variables have not been accepted widely in quantitative fertility studies because some are not easily incorporated into fertility models. Later Bongaarts and Potter (1983) have produced a modified version of the work of Davis and Blake (1956). Diffusion theory exists when the adoption of innovative ideas (and corresponding behavior) by some individuals influences the likelihood of such adoption by others (Montgomery and Centerline, 1993). The core theme of diffusion theory is that people do interact and aside from individuals' role to lower fertility, their preference is always influenced by others' preferences, cultural norms, and societal institutions. They collect information from others and try to act 
upon them. The process of gaining knowledge and the process of influencing others are the two major mechanisms of diffusion (Centerline, 2001).

Among the five development regions of Nepal, in general, the level of social and economic development is highest in the Eastern region, followed by the Central, Western, Mid-western and Far western regions. For example, the human development indices for the Far-western region (0.404) and the Midwestern region (0.402) are lower than the Western (0.491), Central (0.490), and Eastern regions (0.493) (UNDP, 2004).

Tuladhar (1986) has highlighted findings of his studies are; the nature and strength of contraceptive use is closely related with family size; they have had three or more living children with a minimum of one son. He has further concluded that probability of using contraceptive is extremely low if a woman has no surviving son. Duration of marriage is one of the intermediate variables affecting fertility of a society.

Trends in fertility over time can be examined by comparing age-specific fertility rates from the 2011 NDHS for successive five-year periods preceding the survey, because women age 50 or above were not interviewed in the survey, the rates for older age groups become progressively more truncated for periods more distant from the survey date. For example, rates cannot be calculated for women age 35-39 for the period 15-19 years before the survey because these women would have been over age 50 at the time of the survey and therefore not eligible to be interviewed. Nonetheless, the results show that fertility has dropped substantially among all age groups over the past two decades. The decline is steepest among the cohort age 30-34, with a 50 percent decline between the period 10-14 years before the survey and the period 0-4 years before the survey.

Fertility trends are estimated from the data obtained in the 1996, 2001, and 2006 NDHS with information gathered in the 2011 NDHS. Fertility declined from 4.6 births per woman in the 1996 NFHS to 2.6 births per woman in the 2011 NDHS - a drop of two births per woman in the past 15 years. The decline in fertility is most pronounced in the five years between 2001 and 2006 (a one-child decline). Fertility has declined in every age group over the past 15 years, with largest decline seen among women 25-34 years. But over the past 5 years the largest decline is observed among women 20-24 years. Many factors may have contributed to this precipitous decline in Nepal, including improved communication and greater access to modern methods of contraception. Extended spousal separations due to migrants seeking work in foreign countries, especially the Gulf countries and other Southeast Asian countries, may be another reason for the fertility decline. A decline in the ideal number of children, increasing age at marriage, and increasing use of safe abortion services are other factors that could potentially affect fertility. 
NDHS 2011 shows the percent distribution of all women and currently married women by number of children ever born, mean number of children ever born, and mean number of children living. 88 percent of women age 15-19 have never given birth. This proportion declines to 12 percent among women age 25-29 and to 5 percent or less among women age 30 or above, indicating that childbearing among Nepalese women is nearly universal. On average, Nepalese women nearing the end of their reproductive years have attained a parity of 4.6 children. This is two children more than the total fertility rate. The same pattern is replicated for currently married women, except that the mean number of children ever born is higher among currently married women ( 2.7 children) than among all women ( 2.1 children). The difference between all women and currently married women in mean number of children ever born is due to the substantial proportion of young and unmarried women in the former category who exhibit lower fertility.

Similarly NDHS 2011 data highlights the mean number of children ever born and the mean number of children surviving rise with increasing age of women. A comparison of the mean number of children ever born with the mean number of living children reveals the experience of child loss among Nepalese women. By the end of their reproductive years (age 45-49), women in Nepal have given birth to an average of 4.6 children, with 3.9 surviving. Voluntary childlessness is uncommon in Nepal. Currently married women with no children are likely to be those who are sterile or unable to bear children. The level of childlessness among married women at the end of their reproductive period can be used as an indicator of the level of primary sterility. In Nepal, primary sterility among older currently married women is 3 percent.

According to the 2011 NDHS data, birth intervals are slightly longer in urban (40.3 months) than in rural (35.9 months) areas. There are no marked differences in median birth intervals by ecological zones. The median birth interval is longest in the Western region (43.3 months) and shortest in the Far-western region (33.2 months). Birth intervals are longer in the Western terai and Western hill sub regions than in the other sub regions. Birth interval increases with education from 35.1 months among women with no education to 42.2 months among women with an SLC or above. Similarly, birth interval increases with wealth. The birth interval for the highest wealth quintile is nearly 4 years (46.2 months), whereas for all other quintiles it is 37.2 months or less.

The onset of childbearing at an early age has a major effect on the health of both mother and child. It also lengthens the reproductive period, thereby increasing the level of fertility. The median age at first birth is 20.1 years for the youngest cohort of women (age 25-29) for whom a median age can be computed. Almost one-quarter of Nepalese women ( 23 percent) have given birth before reaching age 18, while about half (48 percent) have given birth by age 20 . The median age at first birth is about 20 years across all age cohorts, indicating virtually no change in age at first birth over time (NDHS 2011). 
Acharya (1997) has argued that on the basis of 1976 and 1996 survey data, ages at marriage of woman and child loss experience are still dominant factors of fertility variation. UN (1997) concluded that in Nepal early marriage is considered being the major contribution to a persistent and high fertility level. The findings also indicate that fertility level is correlated with the level of female literacy in the country. Caldwell $(1980,1982)$ has concluded there are numerous channels through which education can affect fertility. Education can provide individuals with a new vision and normative orientation, better health care, better employment, and access to family planning methods and these in turn may produce depressing effect on fertility.

Tan (1987) has found that ethnic composition is to be the strongest determinants of fertility. He has found that ethnic composition indirectly enhance fertility.

Andorka (1978), Li and Wang (1994) and Findley (2005) have characterized the relationship between fertility behavior and place of residence as having a direct linkage. There is a fairly consistent correlation between urban or rural trait of the place of residence and fertility. Similarly, Hoffman-Novoting (1987) asserts that fertility behavior of an individual is connected with structural and cultural characteristics of his/her micro and macro social environment. Boyle (2003) has also stressed the importance of geographical variations in place or context in understanding fertility decision-making of individuals.

Cernic-Istenic and Kveder (2008), posit that fertility behavior of individuals is closely linked with economic and social characteristics of their life settings. However Cernic-Istenic and Kveder (2008) argue that changes in social behavior do not occur quickly, or at the run of one single generation.

Barber et al. (2002) have investigated the effects of average length of the woman's education in Peru. They have concluded that women who spend a long time getting education are likely to have fewer numbers of children than those who spend less or no time at all.

The study has certain constraints such as having small sample size, findings may not be generalized and there are various variables that affect on fertility but a few variables are only concern to this study.

Choice of Variables: Total Children Ever Born (CEB) is taken as dependent variables while other independent variables are taken separately when the impacts of socio-economic and demographic variables are assessed with the set objectives. The study of total Children Ever Born (CEB)- coded by V201 is carried out by calculating the number of children ever born live from women 15-49 years divided by the total number of women in same age group. The independent variables for this study are given below; 
Table.No.1: Notation of the Independent Variables

\begin{tabular}{|l|l|l|}
\hline S.N. & Notations & Independent Variables \\
\hline 1 & V130 & Religion \\
\hline 2 & V149 & Educational attainment \\
\hline 3 & V732 & Employment all year/seasonal \\
\hline 4 & V025 & Type of place of residence \\
\hline 5 & V131 & Ethnicity \\
\hline 6 & V613 & Ideal number of children \\
\hline 7 & V624 & Unmet need \\
\hline 8 & S309 & Age at Marriage \\
\hline 9 & V206 & Son who have died \\
\hline 10 & V024 & Region \\
\hline 11 & V207 & Daughters who have died \\
\hline 12 & S106a & Destination Nepal \\
\hline 13 & S106b & Destination India \\
\hline 14 & S106x & Destination others \\
\hline 15 & Scdth & No of Child Death \\
\hline 16 & V201 & Total Children Ever Born \\
\hline
\end{tabular}

There are several independent variables to analyze the determinant factors of fertility among respondents though only fifteen variables are selected to this study to analyze more precise ways. These fifteen variables are grouped under three main headings to represent various sectors to determine the characteristics of respondents with the help of dependent variable (CEB). These three groups are as given below;

Demographic Variables; V206, V207, S106a, S106b, S106x, Scdth

Socio-Cultural Variables; V130, V149, V024, V131, V025, S309, v613, v624

Economic Variable; V732

\section{Methods and Materials}

\subsection{The Data}

The study is based on the analysis of secondary data obtained from the Nepal Demographic Health Survey (NDHS) 2006, which is nationally representative and have been implemented to allow analysis for Nepal as a whole and separately by rural-urban areas and by development regions. For the analysis, both the household and individual files have been used to obtain the necessary data. The NDHS 2006 was conducted by combined effort of Population Division of Ministry of Health and Population, government of Nepal, NEW ERA and Macro International Inc. which was funded by the United States Agency for International Development (USAID). 
The NDHS is a nationally representative survey of 10,793 women age 15-49 and 4397 men age 15-59.The 2006 NDHS is the comprehensive survey conducted in Nepal as part of worldwide Demographic and Health Survey (DHS). The principal objective of the 2006 NDHS is to provide current and reliable data on fertility and family planning behavior, child mortality, adult and maternal mortality, children's nutritional status, the utilization of maternal and child health services and knowledge of HIV/AIDS.

\subsection{The Methods}

This study presents data through frequency tables, cross tabulation and mean tables. Besides these, correlation and regression analysis are used separately to analyze the relation between fertility on the basis of mean CEB and independent or explanatory variables. Information on number of children born alive (lifetime fertility) includes all children born alive (that is to say, excluding fetal deaths) during the lifetime of the woman concerned up to the census date. The number recorded includes all live-born children, whether born in or out of marriage, whether born in the present or a prior marriage, or in a de facto union, or whether living or dead at the time of the census. Mean number of children ever born to women represents the childbearing experience of a real age cohort and reflects current and past fertility behavior. Finally, CEB does allow for the generalization of data and an understanding that can provide the basis for further analysis. Children ever born, the dependent variable is treated as an interval scale in both bivariate and multivariate analyses. The children ever born to all women irrespective of the age group (lifetime fertility) and women are analyzed separately as a measure of fertility. The demographic, socio-cultural, economic and spatial variables are used as independent variables.

\section{Result and Discussions}

A multivariate analysis has been conducted to measure the effect of various demographic, socio-cultural, economic and spatial variables on fertility (CEB). This study attempts to relate the mean CEB of respondents with their socio-economic and demographic variables. The aim of this study is to obtain difference in the relationship of fertility (CEB) among demographic, Socio-cultural, economic and spatial characteristics of respondents. The different demographic, socio-economic and spatial characteristics of respondents may bring variation in fertility. So the different characteristics have been defined. Some variables have been incorporated in correlation analysis for one to one comparison of the strength of relationship with fertility (CEB).

Two types of analysis- correlation and regression have been applied to reveal the relationship between dependent and independent variables, that is, mean children ever born (CEB) and independent variables (predicators). Karl Pearson's correlation coefficient is calculated to show the relationship of fertility with its demographic, socio-cultural, economic and spatial variables. For this, bivariate correlation with exclude cases pair wise is applied. Cases with missing values for one or both of a pair of variables for a correlation coefficient are excluded from the analysis. Since each coefficient is based on all cases that have valid codes on that particular pair of variables, the maximum information available is used in every calculation. 
Correlation Analysis: Correlation analysis is used to find out the strength of relationship on the basis of one tailed test and two tailed tests due to having different type of hypothesis. About difference it is discussed in the multivariate analysis.

Regression Analysis: Stepwise regression analysis has been undertaken using SPSS software to examine the effect of demographic, socio-cultural, economic and spatial variables on fertility. For analytical study, the variables included are:

Table.No.2: Demographic Variables

\begin{tabular}{|l|}
\hline S309 $=$ Age at Marriage \\
\hline V206 $=$ Son who have died \\
\hline V207 = Daughters who have died \\
\hline V322 = Parity at sterilization \\
\hline V212=Age of Respondent of First Birth \\
\hline V320=Age at Sterilization \\
\hline S106a $=$ Destination Nepal \\
\hline S106b = Destination India \\
\hline
\end{tabular}

Table No.3: Socio-Cultural Variables

\begin{tabular}{|l|}
\hline V130 $=$ Religion \\
\hline V149 $=$ Educational attainment \\
\hline V131 $=$ Ethnicity \\
\hline
\end{tabular}

Economic variables: V732 = Employment

Spatial Variables: V024 = Region

V025 = Type of place of residence

Dependent Variables: V201 = Total Children Ever Born

When all these requested variables are entered then the estimated regression equation becomes:

$\mathrm{CEB}=1.003+0.426 \mathrm{~V} 206+0.430 \mathrm{~V} 207-0.088 \mathrm{~V} 212+0.003 \mathrm{~S} 309+0.068 \mathrm{~S} 106 \mathrm{a}+0.050106 \mathrm{~b}+$ $0.414 \mathrm{~V} 320+0.929 \mathrm{~V} 322+0.009 \mathrm{~V} 024+0.013 \mathrm{~V} 025-0.022 \mathrm{~V} 130+0.000 \mathrm{~V} 131+0.000 \mathrm{~V} 149-$ $0.011 \mathrm{~V} 732+\mathrm{E} \ldots(1)$

Evident from the regression analysis is that son who have died, daughter who have died, parity at sterilization, age at respondent at first birth, age at sterilization, destination Nepal and educational attainment are dominant factors contributing to the CEB size which are significant at above $90 \%$ confidence level. Except destination Nepal other six variables contributing to 
the CEB size which are significant at above $95 \%$ confidence level. Similarly except destination Nepal and educational attainment, others remaining five variables are significantly contributing to the CEB size with $99.9 \%$ confidence level.

Age at marriage has contributed to increase 0.003 points to CEB for every one year change from lower age to higher age. This is not found expected direction and it is statistically insignificant. Religion contributes to decrease 0.022 points to CEB for every change of the religion but it is not found statistically significant. Ethnicity has no specific role to the CEB which contribute 0.000 roles to every change of ethnic groups. Employment contributes to decrease .011 point to CEB for every change of all year to seasonal employment which is not found statistically significant. Similarly region contributes to increase .009 point from eastern to far western which is expected direction but it is not found statistically significant. Type of place of residence contribute to increase .013 point to CEB which is expected direction but found statistically insignificant. Destination India contributes to increase .050 which is found statistically insignificant.

The analysis shows that when other factors are controlled, age of respondent at first birth and educational attainment have remain strong and significant negative impact on fertility at 99.9 percent and 95 percent confidence level respectively. Similarly son who have died, daughter who have died, parity at sterilization and age at sterilization have strong and significant positive impact on fertility at 99.9 percent confidence level. Similarly destination Nepal has strong significant positive impact on fertility at 90 percent confidence level.

The analysis shows that age at marriage, educational attainment, and age of respondent at first birth, destination Nepal, employment and religion have strong negative correlation with fertility. Similarly son who have died, daughter who have died, parity at sterilization, age at sterilization, region, ethnicity, type of place of residence and destination India have strong positive relation with fertility.

The mean CEB (2.45) of respondents shows still high level since it includes 22.57 percent respondent in age group 15-19 and 87 percent of them have never given birth .As a whole their mean CEB is only 0.15. On average Nepalese women nearing the end of the reproductive age group (45-49) has attained a parity of 5.3 children (NDHS, 2006). Similarly mean age of respondent at first order birth is 19.7 . The mean parity at sterilization is 3.79 which shows high figure.

The mean CEB by age at marriage is found very high (3.82). The correlation between mean CEB and age at marriage is negative and it is found statistically significant. But the effect of age at marriage on fertility is not found significant and expected direction it may be the 
high percentage of respondent in low age group where the mean CEB is only 0.15 . So age at marriage should be increased to reduce fertility in Nepal.

The frequency of child death (Sons' death or daughters' death) always leads to increase the fertility of respondent. So to reduce the fertility in Nepal child death should be minimized which is statistically proved.

Sterilized mean CEB is 3.79 which are peculiar in nature compare to general mean CEB (2.45).

The interrelationship with fertility is statistically significant. It is statistically significant to increase fertility. We conclude that sterilization in Nepal is not utilized as its own norms. It is mostly used only those who have had much more children as they desired.

Generally lower age at first birth indicates the higher mean CEB. Mean age of respondents at first birth is 19.37 year. To reduce the fertility in Nepal mean age of first birth should be increased which is statistically approved. Since it is still lowers the fertility is found higher in Nepal.

There is found negative significant relationship between migrants and fertility. But the effect of migrants on fertility is found positively significant since the destination Nepal is categorized in no to yes question, the result says that migrations in Nepal have high positive impact than no migration in Nepal. This may be the causes of women shift from one place to another due to traditional marriage customs which doesnot generally have any impact on fertility.

Similarly respondents whose destination is India are found only 4.32 percent. The category of question is based on No to Yes. The mean CEB of those whose destination is not India has 2.44 while it is 2.46 to those whose destination is India. The correlation is found positive but not significant. Similarly the effect is also not found significant. Even though the result generally indicates that the most of the migrants of Nepal to India is only for their livelihood due to their poor condition so their CEB is slightly high in comparison to other.

Most of the respondents $(86.6 \%)$ are found Hindus while 7.6 percent are Buddhist and then Muslim (3.7\%). Mean CEB is found highest (2.95) in Muslim, the second Hindu (2.45), and then Christian (2.33), Buddhist (2.30) and Kirat (2.13). Since Muslim has strong commitment for not to use family planning devices according to their traditional beliefs in comparison to other religions. The high mean CEB is recorded within the correlation between religion and fertility is negative but insignificant. The effect of religion on fertility is not found significant. This indicates that as a whole there is not found any differentiation between religion and fertility. 


\section{Concluding Remarks}

The mean CEB of those respondents whose education status is zero has 3.53 while other higher level education status has minimized the mean CEB. The correlation between education status and fertility is significantly negative. Its effect on fertility is also found statistically significant. This indicates that fertility of Nepal can be reduced significantly by slightly increasing the educational status of women. The mean CEB by ethnicity is recorded according to national population size. It is generally found higher to those whose population is in minority in comparison to others. We conclude that ethnicity only doesn't impact the fertility in the context of Nepal though its relation to fertility is positive from major proportion group to lower proportion group.

The mean CEB, among those who are all year employed, is 2.88 while it is 2.30 among seasonal working respondents and it is only 0.70 occasional working respondents. The relationship between fertility and employment status is negatively significant. The result indicates that absentees of seasonal and occasional employed with their spouses are higher in comparison to fully employ. But its effect on fertility is found statistically insignificant.

The mean CEB is lowest (2.25) among those who live in Eastern region while it is 2.28, 2.49, 2.64 and 2.68 among respondents who live Western, Central, Far-western and mid- western regions respectively. The relationship between fertility and regions is found positive with statistically significant since regions are categorized from eastern to far western or from forward regions to backward regions based. But its effect on fertility is statistically insignificant.

There are 27.3 percent respondents who live in urban regions while remaining 72.7 percent are in rural areas. The mean CEB is 2.05 among those respondents who live in urban areas while it is 2.59 to those who live in rural areas. The relationship is found positive with statistically significant. But its effect on fertility is statistically insignificant.

Regions, type of place of residents, age at marriage and destination India have weak positive impact on fertility while religion, ethnicity, employment have weak negative impact on fertility. The enter regression analysis accepts seven variables which are involved in this study have significant role to contribute for the variation on fertility. It is very high percentage and it help to bring the best result. The adjusted $\mathrm{R}^{2}$ variation is much more valuable because its value is 0.868 which is very close to the value of co-efficient of multiple determination $\left(\mathrm{R}^{2)}\right.$ i.e., 0.870 . The difference is $.870-.868=.002$ about 0.2 percent. This shrinkage means that if the models are derived from the population rather than a sample it would account for approximately 0.2 percent less variance in the outcome. This indicates the result of regression is much more validated.

The value of $\mathrm{R}^{2}$ is 0.868 . This means 86.8 percent of the variation on fertility is explained only by these five variables. The highest variation is explained by parity at sterilization (i.e., 79.1 $\%$ ). Other variables; son who have died, daughter who have died, age at sterilization and age of respondents at first birth have also brought 6.7 percent variation on fertility. 
Although most of the variables are omitted from the regression that might have a correlation with fertility but their influence is not statistically significant when the five predicted variables are controlled.

This study finds out the major five variables which are found statistically significant. Similarly their impact on fertility is also significant. Son's and daughter's deaths are contributing to increase the fertility so it is strongly recommended that there should be created healthier environment to save the children for reducing the fertility of Nepalese women.

Age at sterilization and parity of sterilizations result shows fertility level bring high. It is the cause of taking sterilization at very late age so there should be increased sterilized clients in their earlier age so that their undesired children can be terminated. Policy makers and implementers should understand that late age sterilization does not negatively impact on fertility as a whole. Age of respondents at first birth is still lower to reduce fertility so it should be increased by rising the age at marriage with special legal condition and increasing educational status of women. Destination Nepal is taken as migration case. It has strong positive impact on fertility. To reduce fertility, migration should be based on out of countries except India.

\section{References}

Acharya, L. B. (1997). Socio-Economic Determinants of Fertility in Nepal. A comparative Analysis of data from the 1970s and 1990s. Paper presented on conference on Fertility Transition in Nepal: Changing Context and Dynamics, Kathmandu, 25-26 November 1997.

Andorka F. (1978). Determinants of Fertility in Advanced Countries. London: Methuen and Co. Ltd.

Andry F. (2005). Discovering Statistics Using SPSS. London:Sage Publication Ltd. Barber

Barber J.S., Pearce.L.D, Chaudhary.Gurung ,s. (2002). Voluntary Association and Fertility Limitation. Nigeria: Soc. Force

Bongaarts, J., and Potter, R.J. (1983). Fertility, Biology and Behaviour: An Analysis of the Proximate Determinants. New York: Academic Press.

Caldwel, J.C. (1997). The Global Fertility Transition: The Need for a Unifying Theory. Population and Development. NewYork.

Caldwell, J.C.(1982). Theory of Fertility Decline. London: Academic press.

Central Bureau of Statistics. (2011). Preliminary Report of 2011, Nepal. Kathmandu. Central Bureau of Statistics.

Cernic, I.M., and Kveder, A. (2008). Urban-rural life setting as the explanatory factor of differences in fertility behaviour in Slovenia. Informatica, Vol. 32, pp. 111-122.

Cutright, P. (1981). The mechanism of demographic change in historical perspective. Population Studies, 35. New York.

Davis, K. \& Blake, J.(1956). Social structure and fertility: An analytical framework. Economic Development and Cultural Change, Vol. 4(3), pp. 211-35. 
Economic and Social Commission for Asia and Pacific (2001). Population Data Sheet 2001. Population and Development Indicator for Asia and Pacific, ESCAP, Bangkok.

Heer, D. (1966). Economic development and fertility. Demography, vol, 3(2), New York.

Hoffman-Novotony, H.J. (1987). The Future of the Family. European Population Conference: Issues and Prospects. PlenarySéances. Central Statistical Office of Helsinki. pp.113-199.

Joshi, P.L. and David, A.S. (1983). Demographic Targets and their Attainments, the Case of Nepal. Kathmandu, National commission on population.

Li, S., \& Wang, W. (1994). The difference in fertility between urban and rural areas and its impact on the process of urbanization. Chinese J. Population Sci., vol. 6(2), pp. 201210.China.

Mason, D. R. and Douglas, A. L. \& William,G. M.(1983). Statistics, an Introduction. New York, Harcourt Brace, Jovanovich, INC.

MOH. (1993).Nepal Fertility, Family Planning and Health Status Survey, 1991. Kathmandu, Ministry of Health.

Ministry of Health., New Era, ORC Macro, et al. (2002). Nepal Demographic and Health Survey 2001. Calverton, Maryland, USA: Family health division, ministry of health Nepal; New Era and ORC Macro.

Montgomery, M. R,\& Casterline, J. B. (1993).The diffusion of fertility control in Taiwan: Evidence from Pooled Cross-Section, Time Series Model. Population and Development Review, vol. 47(3), pp. (n.a.), New York, Population Council.

PAI. (1999). Why population matters? International Edition, Washington D.C., Population Action International.

PRB. (2011). World Population Data Sheet 2011, WashingtonDC. Population Reference Bureau.

Tan, B. A. (1987).Multivariate analysis of the impact and efficiency of the family planning program in peninsular Malaysia. Asia Pacific Population Journal, vol. 2(2), pp, (n.a.).

UNDP.(2004).Reading in human development. Human Development Report Office. New York. United Nations Development Programme.

UNPF.(1999). Population Briefing Kit2000. New York. United Nations Population Fund.

UN. (1973).The Determinants and Consequences of Population Trends; New Summary of Findings on Interaction of Demographic of Economic and Social Affairs. New York. United Nations.

UN. (1983). Manual X. Indirect techniques for demographic estimation.Population Studies, No. 81. New York,United Nations.

WB. (2003). MDG: Reduce by three-quarters, between 1990 and 2015. The maternal mortality ratio. Development Report 2003, Kathmandu. World Bank

Note: Views and opinions expressed in this article are the personal views of author 